\title{
A (in)sustentabilidade do discurso para 0 desenvolvimento sustentável no Banco Mundial
}

\section{Luciano Accioly Lemos Moreira}

Graduado em História, mestre em Educação e

doutorando em Lingūística, na área de Análise do

Discurso, do Programa de Pós-graduaçāo em

Letras e Lingūistica (PPGLL/Ufal). E-mail:

Luciano.almoreira@gmail.com.

Resumo: Demonstração das permanências e rupturas verificadas no âmbito do discurso sobre o desenvolvimento sustentável contido nos projetos do Banco Mundial e da ONU, a partir da década de 1990, com base no referencial metodológico da Análise do Discurso, por meio da observação e compreensão dos processos parafrásticos e polissêmicos em tensão discursiva, assim como da concepção da linguagem em sua capacidade de transformar, induzir e convencer as consciências dos individuos, durante a reprodução e a reprodução ideológica, política e econômica presentes no mundo dos homens.

Palavras-chave: discurso; sustentabilidade; capitalismo; paráfrase; polissemia

Abstract:Demonstration of the continuities and ruptures observed within the scope of the discourse on sustainable development in the World Bank and the UN projects published from the 1990's, having as its reference the methodological procedures from the area of Discourse Analysis, and resorting to the understanding of paraphrastic and polysemic tension, as well as the conception of language in its transformative potential, to induce and convince the individuals' consciousnesses during the ideological, political and economic reproduction present in the world.

Keywords: discourse; sustainability; capitalism; paraphrases; polysemy 

Neste artigo procuraremos refletir sobre a proposta de uma educação para o desenvolvimento sustentável, defendida pela Organização das Nações Unidas (ONU). Ao dialogar com tal projeto, tentaremos explicitar os motivos e as pretensões desse programa para a humanidade. Antes, porém, apresentaremos uma breve explicação do que vem a ser tal órgão internacional, sua função e operacionalidade para a dinâmica do capital.

A Organização das Nações Unidas (ONU) é uma instituição internacional composta por 192 Estados soberanos. Sua fundação se deu após a Segunda Guerra Mundial (1945) e tem, conforme seu programa oficial, o objetivo de promover a paz, a segurança e o progresso entre os povos. Seu programa está contido na carta da ONU, na qual a China, os Estados Unidos, a França, o Reino Unido e a ex-União Soviética estabeleceram os direitos e deveres dos membros da comunidade internacional que participaram de suas assembléias.

A ONU é formada por seis órgãos e tem sua sede situada na cidade de Nova York, nos Estados Unidos. É, ainda, composta por organismos especializados em vários setores estratégicos. Desse modo, está diretamente ligada à Organização Mundial de Saúde (OMS), à Organização Internacional do Trabalho (OIT), ao Banco Mundial, ao Fundo Monetário Internacional (FMI) e à Organizạção das Nações Unidas para a Educação, Ciência e Cultura (Unesco), entre outros. Esses órgãos internacionais, em conjunto, formam o Sistema das Nações Unidas.

O Brasil mantém relação, e também representação, com o Sistema das Nações Unidas através da implantação de projetos em vários setores sociais, políticos, educacionais, culturais e econômicos, assim como através da obtenção de empréstimos e convênios com órgãos das Nações Unidas, voltados aos interesses do capital internacional e local.

Em dezembro de 2002, a Assembléia Geral das Nações Unidas aprovou a Resolução n.o 7/254, a qual determina, a partir de 2005, o início da Década da 
Educação para o Desenvolvimento Sustentável (Deds). A Unesco seria o órgão responsável pela implantação dos projetos educacionais, científicos e culturais elaborados pela ONU, nos países integrantes desse projeto.

O plano elaborado por esse órgão internacional para o Desenvolvimento Sustentável fornece as orientações e conselhos para os países envolvidos, demonstrando os passos que devem ser dados para desenvolver suas economias sem que danifiquem a vida humana e a natureza.

Conforme o documento final da ONU, para a realização de uma educação voltada ao desenvolvimento sustentável (2005, p.28), “os padrões de produção e consumo como evidenciados nas sociedades industrializadas não poderiam ser mantidos, levando em consideração os recursos do planeta". desenvolvimento sustentável se configura, portanto, uma tentativa de implementação de um modelo produtivo capitalista que não coloque em risco a própria existência da humanidade. Assim, do ponto de vista do Sistema das Organizações das Nações Unidas, o sistema produtivo capitalista, a partir do final do século XX e início do século XXI, mostra sinais de destruição e de ameaça à continuidade da vida humana. Esse discurso torna-se evidente quando o projeto afirma que

Poucos objetivos são mais urgentes e críticos para o futuro da humanidade do que assegurar a melhoria constante da qualidade de vida para esta e para as futuras gerações, o respeito a nosso patrimônio comum - o planeta em que vivemos. Como pessoas, procuramos mudanças positivas para nós mesmos, para nossos filhos e netos, devemos fazer isto respeitando o direito de todos de fazer o mesmo. Para isso, devemos aprender constantemente sobre nós mesmos, nosso potencial, nossas limitações, nossos relacionamentos, nossa sociedade, nosso meio ambiente, nosso mundo. A educação para o 
desenvolvimento sustentável é um esforço vital e eterno que desafia indivíduos, instituições e sociedades a olhar para o dia de amanhã como um dia que pertence a todos nós ou não pertencerá a ninguém. (Unesco, 2005, p. 25)

Confirma-se, portanto, que há, na atualidade, problemas na dinâmica do sistema capitalista em continuar o seu funcionamento. Dessa forma, ao enunciar que o "esforço" de todos nós na tentativa de amenização das dificuldades por que estamos passando se tornou "vital e eterno", demonstra-nos a emergencialidade e severidade de tal crise. Assim, a expressão "vital e eterno", que pode ser parafraseada por "essencial e infindável", respectivamente, explicita-nos que tanto o problema como as soluções, do ponto de vista da ONU, não têm uma resolução definitiva, mas apenas uma contínua preocupação e prevenção em relação à sobrevivência do homem e da vida.

Partindo desse pressuposto, o único horizonte possível para a humanidade é a amenização dos efeitos danosos provenientes das relações excessivas entre os homens, e dos homens com a natureza. Com isso, conforme esse corpo legal, a natureza humana é propensa a excessos egoístas e individualistas, restando-nos a assimilação de valores éticos e morais que se coloquem contrários a essa ordem.

\section{Desenvolvimento Sustentável sob o domínio do capital: movimento, permanência e circularidade de um discurso ideológico.}

De acordo com a ONU, o conceito de desenvolvimento sustentável tem sua gênese ainda na década de 70 do século passado. Com isso, em 1972, na cidade de Estocolmo, as Nações Unidas elaboraram sua primeira conferência para discutir o projeto de sustentabilidade para a humanidade. 
Inicialmente, a preocupação do projeto centravase em relação à proteção dos recursos naturais, já que esses mostravam há muito tempo sinais de esgotamento em vários lugares do mundo. Posteriormente, o conceito e o próprio projeto de sustentabilidade ganharam, por parte do mesmo órgão idealizador, uma ampliação, visto que, em 1987, outra comissão da ONU, ligada ao Meio Ambiente e Desenvolvimento, publica uma obra intitulada Nosso futuro comum. Nessa obra, o conceito de sustentabilidade não se restringe apenas a uma ação para o melhor uso dos bens naturais, mas também se refere ao desenvolvimento de outro padrão produtivo, político e cultural, que, por intermédio da educação, deverá ser incutido nos indivíduos. Esses sujeitos, assim educados, agirão sustentavelmente, tanto em seu espaço singular (comunidade, ONG, instituições locais etc.), como também em um nível mais amplo (órgãos internacionais, governos, empresas) em prol de um fim comum.

A definição de sustentabilidade é mais uma vez complementada em 1991 nos seguintes termos: para ocorrer o desenvolvimento sustentável, é imprescindível "melhorar a qualidade da vida humana respeitando a capacidade do ecossistema" (Unesco, 2005, p.36). Nessa reconsideração conceitual, a ONU afirma que é possível instaurar outro modelo desenvolvimentista que alie qualidade de vida e proteção ambiental. Esse padrão produtivo tornaria sustentável o sistema do capital, propiciando a regeneração de todo o ecossistema.

$\mathrm{Na}$ Cúpula de Joanesburgo, em 2002, a ONU amplia outra vez o mesmo conceito, e propõe, numa assembléia geral, que o período de 2005 a 2015 fosse denominado Década da Educação para o Desenvolvimento Sustentável.

Percebemos, por intermédio dos enunciados acima citados, que há um movimento de reelaboração e de ampliação sobre o discurso da sustentabilidade. Recorrendo a Bakhtin (2004, p. 41), ele nos explica que 
A palavra constitui o meio no qual se produzem lentas acumulações quantitativas de mudanças que ainda não tiveram tempo de adquirir uma nova qualidade ideológica, que ainda não tiveram tempo de engendrar uma forma ideológica nova e acabada. A palavra é capaz de registrar as fases transitórias mais íntimas, mais efêmeras das mudanças sociais.

A palavra, portanto, reflete e refrata as relações sociais, demonstrando, nesse movimento discursivo, as rupturas e as permanências históricas ecoadas pelos sujeitos numa dada posição de classe, objetivando um determinado fim. Lembrando Bakhtin (2004, p.46), "o signo é vivo e móvel, sendo capaz de evoluir". Contudo, entendemos que os limites entre o mesmo e o diferente na linguagem, conforme Orlandi (2005, p.36), não se encontram no discurso de maneira estanque e exata, pois há uma tensão entre os processos parafrásticos e polissêmicos. A paráfrase apresenta-se como uma reformulação do já dito, ou melhor, "em todo dizer há sempre algo que se mantém, isto é, o dizível, a memória" (ORLANDI, 2005, p.36). Os momentos da paráfrase no discurso se constituem no retorno aos mesmos campos dos dizeres, ressignificando. A polissemia, ao contrário da paráfrase, demonstra que todo dizer carrega a possibilidade do deslocamento, do equívoco, da ruptura. Orlandi (2005, p.37) explica que, se a "língua não fosse sujeita a falha e o real da história não fosse passível de ruptura, não haveria transformação, não haveria movimento possível, nem dos sujeitos nem dos sentidos". "Do ponto de vista da análise do discurso, a mera repetição já significa diferentemente, pois introduz uma modificação no processo discursivo" (ORLANDI, 2003, p.119).

Assim, o discurso sobre o desenvolvimento sustentável se ancora para ter sentido, num diálogo com outros discursos desenvolvimentistas historicamente formulados, como também num movimento de deslocamento e deriva na própria interioridade conceitual 
do corpus discursivo em análise. Bakhtin (2003, p.297) nos esclarece que

Cada enunciado é pleno de ecos e ressonâncias de outros enunciados com os quais está ligado pela identidade da esfera de comunicação discursiva. Cada enunciado deve ser visto antes de tudo como uma resposta aos enunciados precedentes de um determinado campo (aqui concebemos a palavra "resposta" no sentido amplo): ela os rejeita, confirma, completa, baseia-se neles, subentende-os como conhecidos, de certo modo os leva em conta. Porque o enunciado ocupa uma posição definida em uma dada esfera de comunicação, em uma dada questão, em um dado assunto, etc. É impossível alguém definir sua posição sem correlacioná-la com outras posições. Por isso, cada enunciado é pleno de variadas atitudes responsivas a outros enunciados de dada esfera da comunicação discursiva.

O discurso da sustentabilidade comunica-se de maneira histórica com o ideal desenvolvimentista presente desde a década de 30 no Brasil. A proposta sobre a necessidade do progresso, ao contrário do atraso, das luzes, ao invés das trevas, tem fundamento na ideologia fundada pela modernidade no início do século XVIII, na Europa. Com o pós-guerra em 1945 e a instauração da guerra fria, formam-se dois blocos antagônicos no mundo do capital: o capitalismo e o socialismo real. Nesse contexto, o discurso sobre o lugar dos países pobres é representado pela demarcação entre o Primeiro Mundo (países avançados do capitalismo), o Segundo Mundo (países do bloco comunista) e o Terceiro Mundo (países subdesenvolvidos). Surge por meio dos países ricos capitalistas o enunciado: países "em desenvolvimento". Ou seja, todo país subdesenvolvido que aplicar em sua economia a lógica mercadológica do capital e se mantiver política, econômica e ideologicamente fiel aos interesses 
do bloco capitalista alcançará, em breve, os patamares econômicos e sociais do Primeiro Mundo. Porém, a partir da década de 70, surgem, no cenário mundial, evidências do desgaste natural e social dessa proposta desenvolvimentista, e, com isso, as políticas em análise trazem em seu discurso a proposta do desenvolvimento sustentável. Recorre-se, no momento de crise social e natural ocasionada pelos efeitos do modelo de crescimento econômico dos anos 50, à proposta de desenvolver economicamente um país, de maneira sustentável e equilibrada. $O$ projeto atual de sustentabilidade, sob o ponto de vista do capital, recorre a um deslocamento político-ideológico que possibilite a continuidade da expansão da riqueza capitalista.

O projeto do Desenvolvimento Sustentável surge, dessa maneira, como uma resposta ao padrão produtivo e consumista de um projeto desenvolvimentista que entra em crise. Referindo-se a esse modelo de desenvolvimento, a Organização das Nações Unidas (Unesco, 2005, p.28) nos esclarece que

Os padrões de produção e consumo como evidenciados nas sociedades industrializadas não poderiam ser mantidos, levando-se em consideração os recursos do planeta. Assim como não se poderia impor um modelo de desenvolvimento às nações, supondo o tipo de consumo praticado pelos países industrializados. Embora o crescimento da consciência tenha tido um impacto sobre os sistemas de produção, mudando o estilo de vida, particularmente nos países industrializados, ela também foi direcionada para padrões incompatíveis com a sustentabilidade. Em termos gerais, enquanto a poluição provocada pela produção no mundo industrializado, a carga ambiental derivada do consumo tem crescido inexoravelmente. Cada vez mais é evidente que muitas questões sociais, econômicas e ambientais estão relacionadas entre si, 
como, por exemplo, pobreza, distribuição desigual de recursos, crescimento demográfico, migração, desnutrição, saúde e HIV/Aids, mudanças climáticas, fornecimento de energia, ecossistemas, diversidade biológica, recursos hídricos, segurança alimentar e toxinas prejudiciais ao meio ambiente.

O padrão produtivo e consumista dos países industrializados não pode ser mantido, nem tampouco estendido aos países em desenvolvimento e/ou pobres. Parece-nos, preliminarmente, que, de acordo com a ONU, nos encontramos num beco sem saída, pois os países que já cresceram e, portanto, se encontram, do ponto de vista do sistema do capital, num lugar economicamente privilegiado devem repensar sua produção de maneira sustentável. Por outro lado, os países pobres e em vias de desenvolvimento estão impedidos, em razão da destruição desse modo de produção, de alcançar os patamares de crescimento dos países avançados. Assim, podemos inferir que o tempo para crescer, ampliar-se e alargar-se já passou, sobrando para nós apenas especular o que restou para os países pobres e em desenvolvimento. Num quadro explicativo contido no projeto para o desenvolvimento define-se tal questão:

O crescimento econômico é o maior componente do desenvolvimento. Na verdade, o crescimento econômico, até recentemente foi visto por alguns como o meio e o objetivo do desenvolvimento. Com o crescimento da economia, intensificaram-se as pressões sobre o sistema e recursos naturais da Terra. Desse modo, por exemplo, de 1950 até 1997:

- o uso da madeira para construção triplicou;

- o uso do papel cresceu seis vezes mais;

- a pescaria quase quintuplicou;

- o consumo de grãos triplicou;

- o combustível fóssil quase quadruplicou, e

- os poluentes do are da água multiplicaram-se várias vezes. 
A triste realidade é que a economia continua a crescer, mas o ecossistema do qual o crescimento econômico depende não se expande, criando cada vez mais uma relação sempre mais tensa. (Unesco, 2005, p. 29)

A ONU, ao pronunciar-se sobre "crescimento", dá a entender que esse termo não contém o mesmo sentido de "desenvolvimento". Crescimento econômico apresenta-se como um "componente" do desenvolvimento, ou seja, aquilo que entra na composição de alguma coisa. Nesse caso, crescer não quer dizer desenvolver. Pelo contrário, desenvolver poderá conter aspectos de crescimento, mas, como já vimos em outras passagens do mesmo discurso, nesse momento, o sistema do capital, ao crescer, destrói, e, com isso, desenvolvimento sustentável toma um sentido próprio, necessário ao nosso tempo de crise estrutural do capital.

O conceito de desenvolvimento sustentável transporta, em sua conjugação, a complexidade e a contraditoriedade dos problemas que ele tenta amenizar. Nesses termos, "desenvolver sustentavelmente" seria aperfeiçoar e aprimorar o sistema produtivo e consumista do capital, contornando a destruição da vida humana e da natureza. Essa reordenação de termos de crescimento para desenvolvimento sustentável expressa não somente uma mudança de denominação, mas essencialmente um deslocamento no projeto ideológico das agências do capital para os países avançados e em desenvolvimento. $\mathrm{Na}$ citação abaixo, podemos aferir tal problemática:

Devemos ter o cuidado extremo de considerar a pobreza como a causa do desenvolvimento nãosustentável, pois são os ricos que têm os maiores níveis de produção e consumo não-sustentáveis. Os ricos estão aptos a fazer escolhas, enquanto os pobres, presos em um círculo de privação e vulnerabilidade 
não podem fazê-lo. Enquanto os ricos podem adotar padrões de desenvolvimento sustentável e mostramse relutantes em fazê-lo, os pobres não têm alternativa além de fazer uso do seu entorno imediato. A pobreza está ligada à degradação ambiental, já que os pobres não têm outra escolha a não ser procurar e se beneficiar de recursos naturais escassos, como, por exemplo, usar madeira, como combustível, e água. Problemas de superconsumo e superdesenvolvimento são fatores-chave para a conservação e proteção ambiental e para a produção e o consumo sustentáveis. (Unesco, 2005, p. 29)

Averigua-se (pelo menos nessa seqüência discursiva) que há uma delimitação precisa entre o mundo dos países avançados (industrializados), denominados de "ricos", enquanto, do outro lado, se encontram os países pobres. Isso demonstra e reforça a impossibilidade de alargamento e crescimento econômico industrial para os países pobres, pois a demarcação desse conceito colocado de maneira precisamente binária, ou seja, rico ou pobre, nos sugere que não há no momento um estágio desenvolvimentista que propicie aos países pobres trilhar no objetivo de alcançar os níveis de riqueza das nações industrializadas. Portanto, essa dicotomia deve existir infinitamente, pois, como podemos perceber, não é a pobreza a maior dificuldade para a sustentabilidade do planeta, mas o "superconsumo" e o "superdesenvolvimento", que, como bem sabemos, não são encontrados em países em que a desnutrição e outras simples doenças matam milhares de pessoas. Fernandes (2003, p.250) elucida que essa proposta

é, na verdade, a de uma política ambiental global elaborada e implementada por instituições tradicionalmente responsáveis por assegurar os processos de expansão do capital - de controle, gestão e monitoramento de recursos naturais 
Com isso, o estoque de capital natural imprescindível à produção capitalista será conservado em prol dos interesses dos países desenvolvidos, mantendo a subordinação e a dependência econômica e política dos países periféricos em relação ao centro enriquecido.

O projeto de desenvolvimento sustentável tem um vínculo essencialmente necessário com 0 ideal de globalização. A globalização apresenta-se para a ONU como a existência de um mercado global, harmonioso no qual todos poderão desfrutar das riquezas pluralmente produzidas. Nessa "aldeia global", cada um contribui com quanto e com o que pode. Cada país participa do sistema produtivo mundial colaborando de acordo com suas potencialidades e beneficiando-se harmoniosamente desse sistema. O problema do desenvolvimento econômico e da diminuição da pobreza no mundo nãodesenvolvido se configura um problema de gestão, ou seja, deve-se investir nos nichos de mercado que cada nação tem, potencializando esses recursos, integrandoos à rede mundial de mercado. Da mesma forma que nesse sistema global, cada país participa de um modo economicamente específico. Identificamos, nesse discurso, um silenciamento, pois, na medida em que o mercado global é concebido como um imenso supermercado e cada país representa um setor de oferta de mercadorias das mais diversas e necessárias à demanda dos mais variados clientes, apagam-se, com isso, os lugares ocupados pelos países subordinados e dependentes, como também emudece o poder hierárquico e explorativo das nações subordinadoras presentes na totalidade desse sistema social. Relações entre países que se dão de maneira conflituosa, e, não raras vezes, de maneira belicosa, transmutam-se no projeto de sustentabilidade com vistas à possibilidade da construção de um mundo pacífico e harmonioso.

Se historicamente a sustentabilidade dialoga com outros ideais desenvolvimentistas, atualizam-se as necessidades econômicas e políticas de outra época. Esse 
' BRASIL: JUSTO COMPETITIVOSUSTENTÁVEL. , 2002, p.38 mesmo discurso deriva do seu sentido primeiro, ou seja, a preservação da natureza no tocante aos ditames desse sistema produtivo, a sustentabilidade da vida individual cotidiana, do estado e da própria governança política do planeta. Podemos expor esse deslocamento de sentido contido nos textos em análise (2002):

1. Utilizar os recursos naturais de modo sustentável (p.18);

2. Um Brasil sustentável poderia se apoiar na vantagem comparativa de seus recursos naturais, integrado-os a níveis mais altos de capital humano (p.19);

3. A sustentabilidade da qualidade de vida, definida de modo mais amplo, implica o equilíbrio das finanças públicas e melhor qualidade dos gastos do governo, o que poderia abrir espaço para investimento e manutenção da infra-estrutura (p.19); 4. O desenvolvimento social poderá ser promovido, se for assegurada a ênfase na sustentabilidade da dívida (p.25);

5. Mas muitos dos investimentos necessários para tornar o Brasil mais sustentável, do ponto de vista social e do meio ambiente, são instituições, e as instituições dependem de pessoas que trabalham para elas. O capital humano está na essência dos avanços de longo prazo em produtividade e crescimento (p52).

6. O investimento em pessoas é importante para a construção de um Brasil mais igualitário(52).

Constatamos que o discurso de sustentabilidade se desloca através de efeitos de sentidos, revelando que a natureza e o social se relacionam e se intercomunicam, tendo como eixo central a valorização do capital humano e natural. "A educação gera capital humano e social"; portanto, poderíamos demonstrar da seguinte forma esse movimento diuscursivo: 


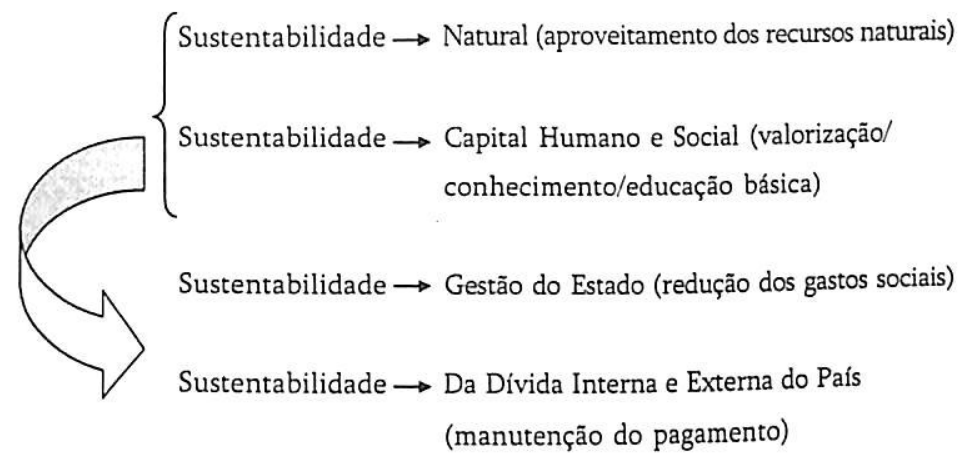

CONSEQUÊNCIA - Sustentabilidade da Pobreza, perenidade da subordinação do Brasil, e dos países pobres a essa dinâmica econômica e política, e circularidade e manutenção do sistema produtivo e reprodutivo do capital.

Exemplificando melhor, poderíamos afirmar que o discurso da sustentabilidade se constitui um projeto político-ideológico que tem como uma de suas funções sustentar esse sistema produtivo e reprodutivo, habilitando, desde as esferas individuais do sistema, do espaço político público, setor privado e governo, para a manutenção dessa forma de sociabilidade. Com isso, mantém-se, pelo menos de maneira ideológica, a circularidade necessária à segurança e ao equilíbrio da exploração do capital sobre a humanidade e a natureza.

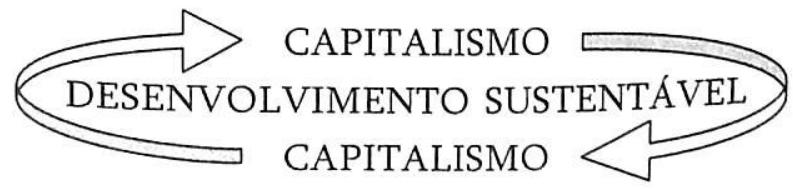

\section{A urgência de novos valores sustentáveis para a sociabilidade do capital}

Ao lançarem as bases para a construção de um mundo sustentável, a ONU e a Unesco definem, conjuntamente, o corpo de idéias e ações que deverão nortear as políticas econômicas, sociais e ambientais, que tanto as nações ricas como as pobres, respeitadas as suas 
especificidades, deverão inserir nos seus projetos de desenvolvimento.

O conceito de sustentabilidade para a Unesco (2005, p. 30) pode ser traduzido nos seguintes termos:

Sustentabilidade refere-se às maneiras de se [sic] pensar o mundo e as formas de prática pessoal e social que levam a:

จ Indivíduos com valores éticos, autônomos e realizados;

- Comunidades construídas em torno de compromissos coletivos, tolerância e igualdade;

$\diamond$ Sistemas sociais e instituições participativas, transparentes e justas; $\mathrm{e}$

$\diamond$ Práticas ambientais que valorizem e sustentam a biodiversidade e os processos ecológicos de apoio à vida.

Na visão desse órgão internacional, deve-se pensar e agir diferentemente, para que o processo de sustentabilidade do homem e do planeta se inicie. Se observarmos a seqüência discursiva acima citada, perceberemos que a mudança se dá de maneira ascendente, ou seja, deve-se primeiramente transformar o indivíduo e, em seguida, a comunidade; posteriormente, os sistemas e instituições sociais; e, por último, o meio ambiente. $\mathrm{O}$ indivíduo converte-se, dessa maneira, no principal agente de mudança. Sem a sua inserção, os outros lugares sociais e o próprio meio ambiente não poderão ser alterados para a dinâmica da sustentabilidade. Por esse motivo, a educação torna-se, nesse momento, o principal lugar de propagação ideológica desse projeto de desenvolvimento. Para demonstrar essa questão, recorreremos ao documento da Unesco (2005, p. 43):

A educação constitui o pilar central das estratégias para promover e enraizar os valores e comportamentos que o desenvolvimento 
sustentável exige. Como alguns pensadores assinalaram: "necessita-se de uma educação transformadora: uma educação que contribua a tornar realidade as mudanças fundamentais exigidas pelos desafios da sustentabilidade. Para acelerar o progresso em direção à sustentabilidade é necessário tornar as relações entre os seres humanos e o mundo natural mais calorosas e afetuosas, e buscar formas de desenvolvimento ambientais e sociais mais responsáveis". A educação nos habilita como indivíduos e como comunidades a compreendermos a nós mesmos e aos outros e as nossas ligações com um meio ambiente social e natural de modo mais amplo.

A educação, dentro dessa proposição, configurase no "pilar" para tal projeto. Desse modo, o termo exposto atribui como sentido para a atividade educativa o lugar de alicerce, no qual tem função central no enraizamento dos valores e comportamentos imprescindíveis para tal tarefa. Conforme a Unesco (2005, p. 43), a educação detém um papel-chave ao "inspirar a crença que cada um de nós tem o poder e a responsabilidade de introduzir mudanças positivas em escala global". Confirma-se a recorrência atribuída ao indivíduo, quanto à sua capacidade em operar mudanças no modo produtivo e consumista insustentável do capital da atualidade. Seu poder poderá transformar positiva e globalmente a negatividade e destrutividade desse sistema. E a educação, como já explicitado, carrega em sua essencialidade a missão de embutir "valores, comportamentos e estilos de vida necessários para um futuro sustentável" (Unesco, 2005, p. 44).

As relações entre os indivíduos em todos os setores sociais, políticos e culturais devem, por esse cabedal de idéias, ser modificados e ressignificados em prol da paz, da justiça, da negociação, da igualdade, do respeito e da compreensão. Outros 
valores e comportamentos de acordo com a ONU, fundados nos direitos humanos e no respeito à natureza, influirão diretamente numa transformação de um modelo de desenvolvimento destrutivo atual, direcionando-o para outro que garanta a existência presente e a futura da humanidade.

Por esse intermédio, podemos inferir que o problema do desenvolvimento voltado à destruição da sociedade e do meio ambiente está fundado numa falta de consciência dos indivíduos em operar relações consigo e com o mundo apoiados por valores sustentáveis.

\section{Da (in)sustentabilidade do controle político do capital à sustentabilidade do controle social para além desse sistema}

Ao expormos tal programa político-ideológico da ONU, em campanha com a Unesco de uma educação para a sustentabilidade do capital, lançamos uma luz sobre os motivos de tal tarefa histórica, suas intenções e propostas em relação a possibilidades de uma saída política para a humanidade. Crescer e destruir de acordo com a ONU é uma dinâmica de um modelo de desenvolvimento não mais saudável e possível em nossa época; já, por outro lado, desenvolver sustentavelmente torna-se garantia de um presente e de um futuro para a vida humana. Esse corpo de idéias defende que é possível impor uma lógica circular à dinâmica expansiva e acumulativa do capital, ou seja, podem-se infinitamente perpetuar as relações de produção e de consumo do mercado capitalista, bastando, para isso, humanizar e harmonizar tal relação.

O capital, porém, configura-se uma forma de relação social produtiva voltada exclusivamente para o acúmulo e expansão de riqueza. Essa riqueza tem como fundamento social a extração, por parte do capitalista, da mais-valia do trabalhador assalariado e a realização dessa riqueza em dinheiro no mercado consumidor. Com isso, a lógica desse sistema, por sua própria natureza e dinâmica, não pode contemplar nem conhecer outra direção e fim 
que não sejam a obtenção e o entesouramento de uns poucos pela exploração de uma maioria trabalhadora. Essa lógica produtiva e reprodutiva sociometabólica tem como fim o valor de troca e não o valor de uso, ou seja, o valor de uso que seria o mesma coisa que a produção para as necessidades humanas transforma-se em meio para a compra e venda de tudo e de todos, até mesmo do próprio ser humano. Meszáros (2002, p.611) expõe de maneira esclarecedora tal questão:

O ter domina o ser em todas as esferas da vida. Ao mesmo tempo, o eu real dos sujeitos produtivos é destruído por meio da fragmentação e da degradação do trabalho à medida que eles são subjugados às exigências brutalizantes do processo de trabalho capitalista.

Bakhtin (2004, p.46) nos chama atenção para o fato de a palavra carregar, em seus efeitos de sentido, as contradições de uma sociedade de classe:

O ser, refletido no signo, não apenas nele se reflete, mas também se refrata. O que é que determina esta refração do ser no signo ideológico? O confronto de interesses sociais nos limites de uma só e mesma comunidade semiótica, ou seja: a luta de classes

Todo enunciado ecoa vozes da permanência, da conservação, da ressignificação, como também da ruptura. Dessa forma, a insustentabilidade política da economia capitalista nos impõe como seres sociais que somos respostas às demandas históricas de nossa época:

As forças matérias e sociais geram situações revolucionárias, que só se efetivam em revoluções pela intervenção do fator subjetivo, que jamais perde seu caráter alternativo, ou seja, se trata de uma decisão humana. (VAISMAN, 1989, p. 428) 
Assim, concordamos que, se a insustentabilidade do modo de produção capitalista se encontra na base produtiva e reprodutiva da sociedade capitalista, apenas será possível a efetiva sustentabilidade da humanidade numa outra forma radicalmente contrária a essa dinâmica social. Mészáros indica os fundamentos essenciais dessa outra ordem produtiva para além do capital:

Portanto, apenas a auto-realização por meio da riqueza (e não pela produção de riqueza alienante e reificada), como a finalidade da atividade-vital dos indivíduos sociais, pode oferecer uma alternativa viável à cega espontaneidade autoreprodutiva do capital e suas conseqüências destrutivas (2002, p. 613)

O caminho para a extinção dessa ordem terá de ter como base fundante o trabalho livre e associado, no qual o trabalhador deterá o controle consciente da produção em todas as suas esferas; e as relações sociais terão como única finalidade as reais necessidade humanas.

Concluindo, entendemos, como nos dizia Marx, que as idéias dominantes de uma época são as da classe dominante; mas, do mesmo modo, recorrendo a Pêcheux (2002, p. 56), acreditamos que "não há identificação plenamente bem-sucedida, isto é, ligação sócio-histórica que não seja afetada de uma maneira ou de outra, por uma infelicidade". Encontramo-nos nesse momento, portanto, numa encruzilhada, pois a alternativa entre socialismo ou barbárie resume-se, nos dias de hoje, apenas à primeira alternativa. Já a segunda opção encontramo-la em todos os cantos do planeta. Basta olharmos ao nosso redor. 


\section{Referências}

BANCO MUNDIAL. Brasil: Justo, competitivo e sustentável uma contribuição para o debate. Nova York, Washington, D.C. USA, 2002.

BAKHTIN, Mikhail. Marxismo e filosofia da linguagem. Trad. de Michel Lahud e Yara Frateschi Vieira. São Paulo: Hucitec, 1979.

BAKHTIN, Mikhail. Estética da criação verbal. São Paulo: Martins Fontes, 2003.

FOLADORI, Guillhermo. Limites do desenvolvimento sustentável. São Paulo: Imesp, 2001.

FOSTER. John Bellamy. A ecologia de Marx: materialismo e natureza. Rio de Janeiro: Civilização Brasileira, 2005.

MÉSZÁROS, István. Para além do capital. São Paulo: Boitempo, 2002.

MÉSZÁROS, István. Produção destrutiva e estado capitalista.

São Paulo: Ensaio,

ONU. Declaração do Milênio - Cimeira do Milênio. Nova Iorque, 2000.

ORLANDI, Eni. Interpretação: autoria, leitura e efeito do trabalho simbólico. Rio de Janeiro: Vozes, 1996.

ORLANDI, Eni. Análise de discurso: princípios e procedimentos. 6. ed. Campinas: Pontes, 2005.

ORLANDI, Eni. A linguagem e seu funcionamento: as formas do discurso. 4. ed. Campinas: Pontes, 2003.

PECCHEUX, M. O discurso: estrutura ou acontecimento.

Campinas: Pontes, 2002. 
UNESCO. Década da educação das Nações Unidas para o desenvolvimento sustentável, 2005 - 2015: documento final do esquema internacional de implementação. Brasília, 2005.

VAISMAN, Ester. A ideologia e sua determinação ontológica. Revista Ensaio, São Paulo: Ensaio, nº. 17/18, 1989. 